\title{
AN IN VITRO COMPARISON OF THE APICAL SEAL PRODUCED BY THREE DIFFERENT THERMOPLASTICIZED GUTTAPERCHA OBTURATION TECHNIQUES IN OVAL CANALS
}

\section{Geetanjali Bansal $^{1}$, Ajay Bansal ${ }^{2}$, Bhupinder Kaur Padda ${ }^{3}$}

${ }^{1}$ Sr. Lecturer, Department of Conservative Dentistry \& Endodontics, Himachal Institute of Dental Sciences, Himachal Pradesh, India

${ }^{2}$ Reader, Department of Prosthodontics, Bhojia Dental College \& Hospital, Himachal Pradesh, India

${ }^{3}$ Professor \& Head, Department of Conservative Dentistry \& Endodontics, Swami Devi Dyal Dental College, Haryana, India

\begin{abstract}
-
\section{ABSTRACT}

The aim of this study was to evaluate and compare the sealing ability to obturate oval canals with three thermoplasticized guttapercha obturation techniques taking lateral condensation technique as the control. Ninety-five freshly extracted teeth were decoronated at $2 \mathrm{~mm}$ coronal to CEJ. Biomechanical preparation was done using step back technique. The teeth were divided into three experimental groups of 30 teeth each and one control group of 5 teeth. The group I (control group) was obturated with lateral condensation technique, group II obturated with injectable thermoplasticized guttapercha technique, group III obturated with thermoplasticized guttapercha with downpack and backfill technique and group IV obturated with core carrier thermoplasticized guttapercha technique. The sealability of each technique was assessed by a dye penetration method. The roots were given two full layers of nail polish varnish except apical $2 \mathrm{~mm}$. Specimens were then immersed in India ink for 48 hours. Robertson's technique was used to clear the specimens. The linear dye penetration was measured from anatomic apex to the deepest extent of dye penetration in a coronal direction using triocular stereomicroscope at $10 \mathrm{x}$ magnification. The mean dye leakage of group I was $2.6700 \mathrm{~mm}$; group II $0.1713 \mathrm{~mm}$; group III $3.3977 \mathrm{~mm}$; group IV $2.3210 \mathrm{~mm}$. When the means of all the four groups were compared using Kruskal Wallis test the difference was found to be very highly significant with the value $<.001^{* *}$, meaning there by that group II is significantly better than the other three groups as far as sealing ability is concerned.
\end{abstract}

Keywords: Apical Seal, Lateral Condensation, Injectable Thermoplasticized Guttapercha, Downpack and Backfill, Thermaflo

\section{INTRODUCTION}

The success of endodontic treatment depends on three dimensional obturation of the root canal space with an inert filling material and creation of the hermetic seal, which will hinder the invasion of microorganisms. Washington study has attributed nearly $60 \%$ of the endodontic failures due to incomplete obturation of the root canal system. ${ }^{1}$ A fluid tight seal in apical third is most difficult to achieve due to anatomy of that area for which the obturating material/ technique need to possess specific qualities.

Lateral compaction of guttapercha is the most widely used technique of obturation of root canal system and often has been used as the standard to which the sealing ability of new filling techniques or materials are compared. ${ }^{2}$ The disadvantages of this technique as enumerated by Brayton et al as creation of voids, lack of homogeneity of the guttapercha mass a high percentage of sealer in the apical portion of the canal, spreader tracts, inadequate spreader penetration in curved canals, lack of adaptation to canal walls, cul-de sac, fins etc. ${ }^{3}$

The condensation pressure required for proper compaction in cold lateral condensation technique leads to higher incidence of vertical root fracture as reported by Meister et al, Gimlin et al. ${ }^{4,5}$ Furthermore the round and conical shaped canals are easier to obturate with 
this technique than the ribbon and oval shaped canals as the area beyond the reach of mechanical action of endodontic instruments in canal will frequently be left unfilled. ${ }^{6}$ These disadvantages of lateral compaction techniques can be overcome by plasticizing guttapercha for root canal obturation.

The injection moulded thermoplasticized guttapercha technique was introduced by Yee et al in 1977. ' Heating of the guttapercha was done to plasticize the guttapercha so that it would flow. The technique "could obturate fins, cul de sacs and minute intracanal communications". Though various authors have stated that the technique has disadvantages like lack of material control, excessive canal enlargement to accommodate the injection needles, lack of measurement guidelines to monitor the progress of filling procedure, the rapid cooling of the material, resulting in poor condensation and voids, the potential for equipment related problems such as needle breakage, or guttapercha leaks and presence of under condensed, slender filling in the apical third of the canal. ${ }^{8}$ This technique also causes a temperature rise on the external root surface which results in potential damage to the root cementum, periodontal ligament and alveolar bone because the excessive rise in intracanal temperature. ${ }^{9}$

The $\mathrm{E} \& \mathrm{Q}$ system is a relatively new introduction to the endodontic armamentarium for root canal filling, works on principle of continuous wave of compaction by Buchann in 1996 which is used in a similar manner as the System B technique for downpack of guttapercha in the apical region to prevent extrusion of guttapercha into periradicular area. ${ }^{2,10}$ The system consists of a control unit with a pen grip device holding a heating tip, as well as guttapercha injection gun (like OBTURA II) for backfill the middle \& coronal portion of the root canal. $^{2}$

In 1978, Johnson described a technique in which mynol guttapercha moulded on a last size of $\mathrm{K}$ file was heated in flame and carried to the root canal coated with sealer. ${ }^{11}$ This idea was later commercialised as Thermafil (Dentsply). Thermafil obturators are made of plastic core coated with alpha phase guttapercha. This stereoform of guttapercha is considered to have better flow characteristics when molten than beta phase guttapercha.
Apical seal is perhaps one of the prime determining factors in evaluating the success of an obturating technique. Dye penetration method is one of the most common methods used for detection of micro leakage as it is easy to use does not require any specialized equipment and is non time consuming.

The amount of dye leakage can be studied either by sectioning, or by clearing the teeth. Robertson (1980), revealed that the clearing technique used to assess the dye penetration is simple, inexpensive, allow three dimensional view and avoids the potential hazards of, loosing any tooth structure while sectioning. ${ }^{12}$ As it is possible to inspect the adaptation of guttapercha to the root canal walls directly in the cleared specimens and dye leakage to its maximum extent all around the specimen

The present in vitro study was undertaken to compare and evaluate the sealing ability of three different thermoplasticized guttapercha obturation techniques: injectable thermoplasticized guttapercha, thermoplasticized guttapercha with downpack and backfill, and core carrier thermoplasticized guttapercha taking lateral condensation technique as the control in oval root canals. This was done by using the time tested dye leakage method and clearing technique.

\section{MATERIAL \&METHODOLOGY}

Ninety five freshly extracted sound single rooted teeth with oval canals were selected. Selected teeth were radiographed from the bucco lingual and mesio distal aspects to verify the patency of the canal. All the selected teeth were decoronated $2 \mathrm{~mm}$ above the cemento enamel junction. Endodontic access cavity was prepared establishing straight line access for each root canal. The working length was determined by introducing no.10 stainless steel K-file into the canal until it appeared at the level of anatomical apex, while the stopper rested at the flat coronal surface. From this measured length $1 \mathrm{~mm}$ was subtracted to get the actual working length. Biomechanical preparations of all selected teeth were done with reamers (Mani, Japan) and $\mathrm{K}$ files (Mani, Japan) by conventional step back technique. Samples were radiographed from the bucco lingual and mesio distal aspects to verify the patency of the canal. After cleaning \& Shaping, the prepared teeth 
were randomly divided into 4 groups in which group I (control group) had 5 teeth and group II,III,IV had 30 teeth each.

Group I: Cold Lateral Condensation Technique (Control group): The Five teeth in this group were obturated by the lateral condensation technique using ZOE as a sealer and 2\% ISO standardized guttapercha cones (Dentspy).

Group II: Thermoplasticized injectable Guttapercha technique with E \&Q Plus Gun (Meta Biomed): ZOE sealer was mixed and applied into the canal as in cold lateral condensation. The Guttapercha Bar was placed into the activated Gun and the gun needle was inserted into the root canal up to $2 \mathrm{~mm}$ short of working length (Figure 1). The trigger was pulled slowly and backfill was done up to the root canal orifice. During backfill gun needle was pushed back simultaneously by guttapercha being filled. The heated guttapercha was compacted with the adequate sized hand plugger that led to complete obturation of the root canal system.

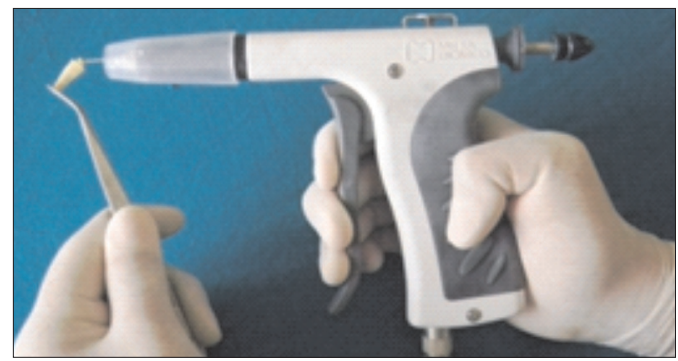

Figure 1: Specimen obturated with Injectable

Thermoplasticized guttapercha technique using E\& Q gun

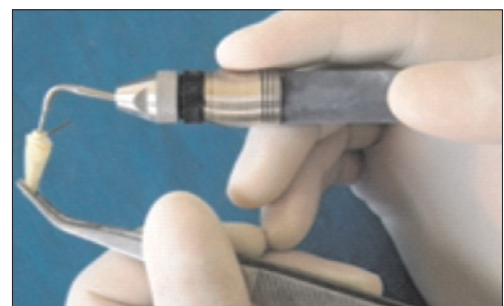

Figure 2: E \& Q pen activated with finger touching the spring

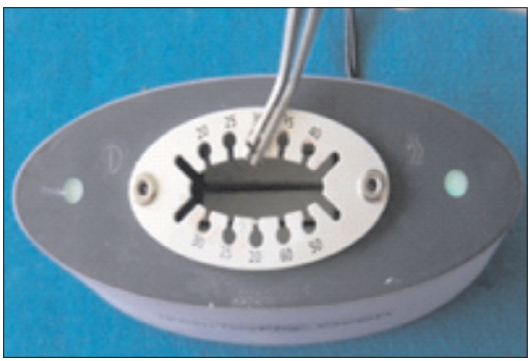

Figure 3: Insertion of obturator in preheated Thermaflo oven
Group III: Thermoplasticized Guttapercha Downpack \& Backfill technique with E \& Q Plus (Meta Biomed)

Obturation involved 2 Steps

\section{Vertical condensation or down packing:-}

A master cone was selected according to the last apical file was used. ZOE sealer was mixed and applied into the canal as in cold lateral condensation, following which master cone was placed $1 \mathrm{~mm}$ short of working length.Appropriate temperature of E \& Q Pen $\left(250^{\circ} \mathrm{C}\right)$ was set and activated by touching the spring switch on the hand piece. The excess of guttapercha over the orifice was severed off first using the activated E \& Q pen tip (Figure 2). The guttapercha was warmed by inserting the pen tip $7 \mathrm{~mm}$ short of working length.At this canal length, activated pen tip was placed for 2-3 seconds and then deactivated for 8-10 seconds as spring switch is released so that apical guttapercha was uniformly warmed. Finally the pen tip was again activated for two seconds so that guttapercha in coronal
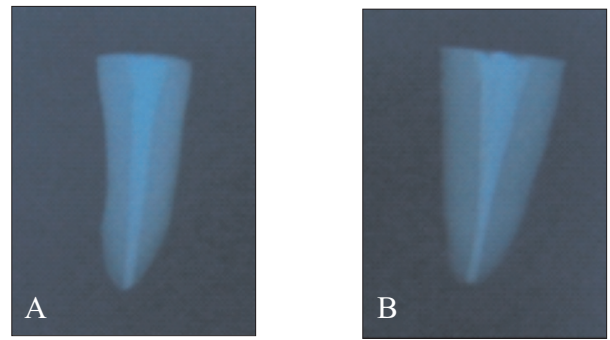

Figure 4: Radiographic view of specimen after obturation Buccolingual view

Mesiodistal view

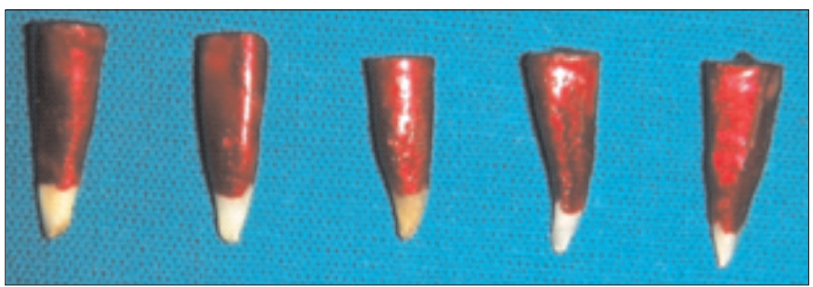

Figure 5: Nail Varnish applied leaving apical 2mm
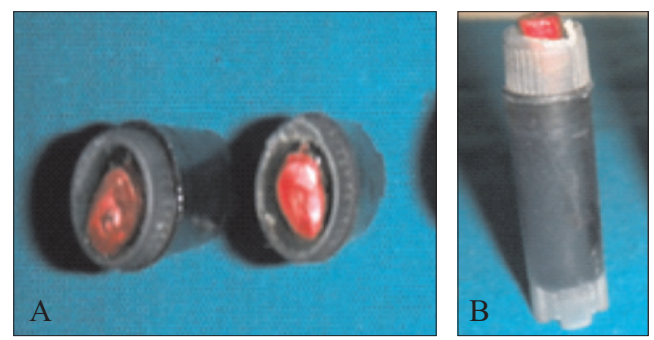

Figure 6: (A) Dye immersion of specimen in plastic vial from above view (B) Specimens suspended upright in black India ink for passive dye immersion 
portion was retrieved. This procedure also prevented the retrieval of guttapercha from the apical portion. The softened guttapercha was compacted with the adequate size plugger, which led to perfect obturation of the apical area \& accessory canals .

Backfill:- The middle and coronal third was backfilled same as with E \& Q gun as in group II.

Group IV: Core Carrier Obturating Technique with Thermaflo (Equinox)

Select the verifier of the same size as the largest hand file used to the working length. Obturator was selected one size smaller than the last size verifier used. Thermaflo oven was preheated. The selected obturator was then placed in the opening of oven that matches the obturator size then we waited till the time the lights of oven on both side turn green (Figure 3). That was the indication that the guttapercha has softened to the right consistency. Till the time obturator was heated, ZOE sealer was mixed and applied into the canal as in cold lateral condensation. The obturator was removed from the oven .Firm apical pressure, without rotation and twisting, was used to seat obturator to previously determined working length. Wait until the guttapercha had cooled and hardened before attempted to break off the excess shaft.

All samples were radiographed from the bucco
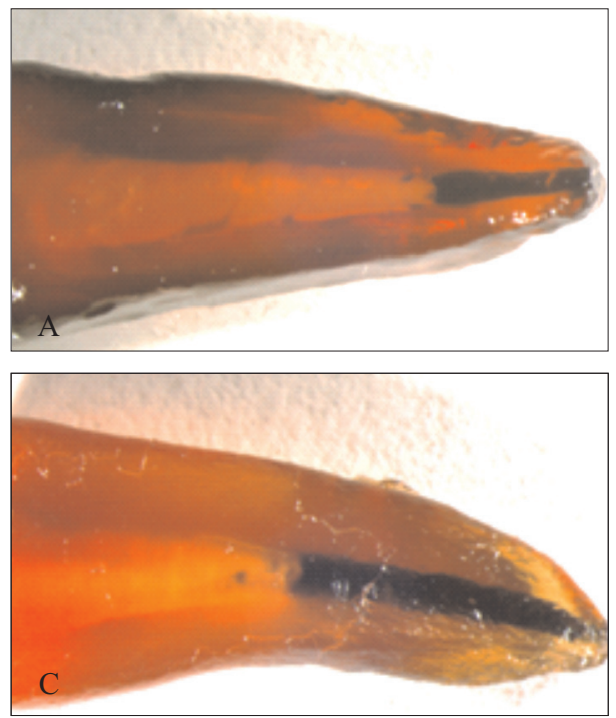

lingual and mesio distal aspects to verify the obturation (Figure 4). After the obturation, coronally the specimens were filled with glass ionomer cement, $2 \mathrm{~mm}$ in thickness to achieve adequate coronal seal. All the obturated specimens were then stored at $37^{\circ} \mathrm{C}$ for $6-7$ days at $100 \%$ humidity to allow root canal sealer to set.

All the specimens were taken out from water and dried. The roots were given two full layers of nail polish varnish except $2 \mathrm{~mm}$, apically to lateral leakage from root surface (Figure 5). Specimens were then immersed in India ink for 48 hours; keeping in mind that they are in upright position and the apices of roots do not touch the floor of container (Figure 6). After 7 days the specimens were removed and rinsed with tap water for 5 minutes to remove excess dye and varnish was removed with acetone. Specimens were then cleared using Robertson's technique with the help of nitric acid, ascending concentrations of alcohol, and methyl salicylate.

The extent of apical dye penetration into root canal system from anatomic apex to the deepest extent of dye penetration in a coronal direction in all the four groups were analysed using Triocular Stereomicroscope at $10 \mathrm{x}$ magnification (Leica, Germany). The dye penetrations in magnified images were measured in millimetres using AutoCAD software. The results obtained from each group (Figure 7) were compared

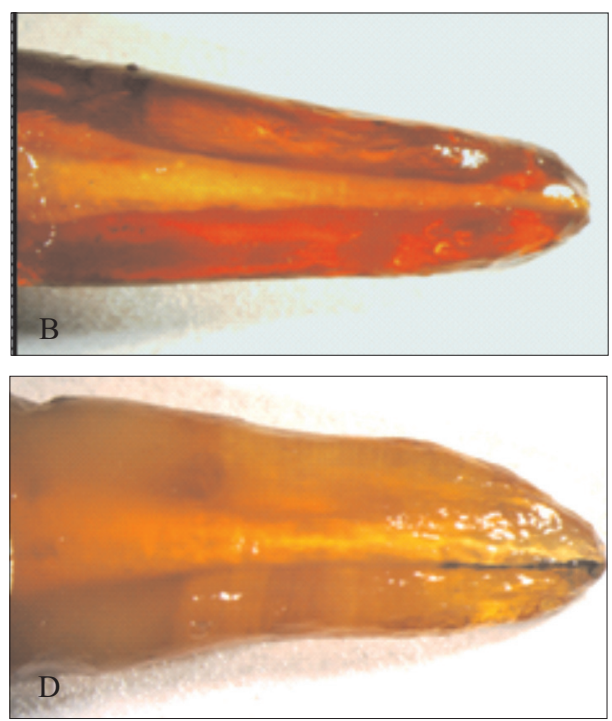

Figure 7 A: Specimen obturated with Lateral condensation technique showing $4.54 \mathrm{~mm}$ leakage.

B: Specimen obturated with injectable thermoplasticized guttapercha technique showing zero Leakage.

C: Specimen obturated using Thermoplasticized guttapercha down pack and backfill technique showing $7.19 \mathrm{~mm}$ leakage.

D: Specimen obturated using core carrier technique showing $3.91 \mathrm{~mm}$ leakage. 
and put under statistical analysis by intercomparison between all groups using kruskal-Wallis test and comparison between each group using Mann-Whitney test.

\section{RESULTS}

Table I summarizes the mean values, standard deviation and statistical analysis for linear dye penetration for all obturation techniques used shows that the mean of dye penetration was found to be highest for group III and the lowest in group II .When the means of all the four groups were compared using Kruskal Wallis test the difference was found to be very highly significant with the value $<.001^{* *}$ meaning there by that group II is significantly better than the other three groups as far as sealing ability is concerned.

On comparing the dye penetration of group I with group III, and group I with group IV using Mann -Whitney test the difference was found to be statistically insignificant with $\mathrm{p}$ value of .451 and .637 respectively. In other words, the dye leakage of group I and group III also group I, group IV was comparable. Whereas when rest of groups were statistically compared with each other the results were highly significant with $\mathrm{p}$ value for dye penetration being $<.001 * *$.

\section{DISCUSSION}

An advantage of in vitro testing methods is that they provide an environment for technique examination and observation without many of the restrictions when doing so in the clinical setting. As obturation of round canals is much easier than the obturation of irregular oval or ribbon shaped canals because of the guttapercha cones being round in form and for obturation of irregular canals compaction is the most important factor for complete obturation. Hence oval shaped canals were chosen for the present study.

Root canals were prepared by conventional step back technique, described by Grossman as this method is the time tested method produces a significant increase in canal area and is more effective in removing predentin \& debris and planning of canal walls. ${ }^{13}$ Tagger and co-workers reported no leakage of the dye when alpha acting guttapercha or lateral condensation with sealer was used. ${ }^{14}$ In this study ZOE sealer was used during obturation because it is most popular and widely used sealer till date also it is cost effective, easy to manipulate and has most of the properties of an ideal root canal sealer. Only apical $2 \mathrm{~mm}$ of the specimens was left uncovered with nail varnish because that is the area where maximum number of lateral \& accessory canals are present which if left unfilled will lead to microleakage. Similar views have been expressed by Abarca et al. ${ }^{15}$

The leakage marker used in this study was India ink because Fox and Gutteridge in 1997 suggested that methylene blue particles dissolves during the process of decalcification and clearing of teeth and the end point of the dye penetration is sometime difficult to determine whereas particles of india ink remain stable thus enabling a better view for evaluating the exact extent of dye penetration. ${ }^{16}$ In this study specimens were placed in upright position for dye penetration as Katz et al observed more linear leakage in teeth placed in dye with apices in upright position than teeth placed horizontally in dye. ${ }^{17}$

Forty eight hours were selected as the time of dye immersion. Pathomvanich and Edmunds described that 48 hours of dye exposure to be sufficient to allow maximum dye penetration in root canal. ${ }^{18}$

The amount of dye leakage was studied by clearing the teeth as Robertson in 1980 revealed that the clearing technique used to assess the dye penetration is

Table 1: Mean Dye Penetration Values

\begin{tabular}{|l|c|c|c|c|c|c|}
\hline \multicolumn{7}{|c|}{ Dye penetration in mm } \\
\hline Group & Mean & $\mathbf{N}$ & Std. Deviation & Minimum & Maximum & Median \\
\hline Lateral condensation (Control) & 2.6700 & 5 & 2.09124 & .80 & 5.31 & 1.5000 \\
\hline $\begin{array}{l}\text { Injectable Thermoplasticized guttapercha } \\
\text { using E \& Q GUN }\end{array}$ & 0.1713 & 30 & .35480 & .00 & 1.57 & .0000 \\
\hline $\begin{array}{l}\text { Thermoplasticized guttapercha technique with } \\
\text { Downpack \& Backfill using E \& Q Plus }\end{array}$ & 3.3977 & 30 & 1.78249 & .00 & 7.19 & 3.1400 \\
\hline $\begin{array}{l}\text { Core Carrier Thermoplasticized guttapercha } \\
\text { technique using Thermaflo }\end{array}$ & 2.3210 & 30 & 2.13981 & .00 & 8.22 & 2.4350 \\
\hline Total & 2.0005 & 95 & 2.08931 & .00 & 8.22 & 1.3700 \\
\hline
\end{tabular}




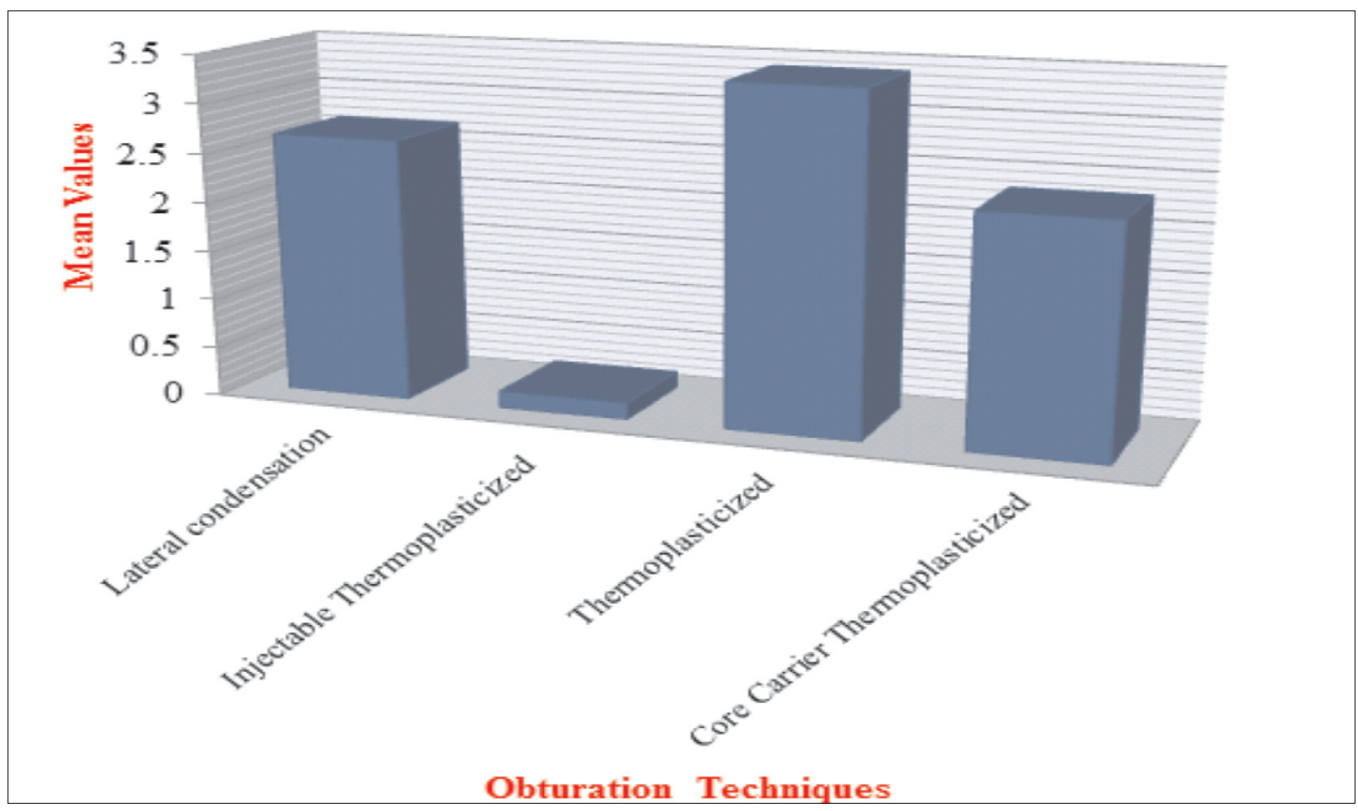

Bar Diagram Showing the Comparison of Mean Leakage of All the four Groups

simple, inexpensive, allow three dimensional views and avoids the potential hazards of loosing any tooth structure while sectioning. ${ }^{12}$

The better performance of injectable thermoplasticized guttapercha in comparison to other technique has been explained by the ability of material to flow laterally and vertically allowing for compaction because of its plasticity, providing excellent surface adaptation ensuring a dense root fill. Similar views have been expressed by Prashanth et al who further state that with this technique the material was able to replicate the canal irregularities $\&$ give an impression like reproduction. ${ }^{10}$

Also the results of this study are in concurrence with those of Torabinejad and MC Robert A.S. et al who found that root canal fillings resulting from injection of thermoplasticized guttapercha were significantly better than lateral condensation technique because they showed close adaptation to the dentin walls with only occasional minor voids whereas fillings produced by lateral condensation technique showed poorer adaptation to the dentin walls. ${ }^{19,20}$ Also $\mathrm{Wu}$ et al postulated that area beyond the reach of the mechanical action of endodontic instruments in canal with oval shapes can be frequently left unfilled when the cold lateral condensation technique is used. ${ }^{6}$

The probable cause for more leakage with E \&
Q plus with down pack backfill technique was lesser percentage of guttapercha filled area. Same view was given by Prashanth et al as they reported that Obtura II showed significantly higher percentage of guttapercha filled area than E \& Q plus with down pack backfill technique,because of inability of heat of $E$ \& $Q$ pen tip to be transferred to the apical region, the result would be an un-adapted guttapercha in the apical region. ${ }^{10}$

The result of our study was in concurrence with Weller et al who reported better adaptation of obtura II with canal wall than thermafil due to stripping of guttapercha from carrier surface during insertion as this will result in lesser percentage of guttapercha filled area with thermaflo as compared to injectable thermoplasticized guttapercha. ${ }^{21}$

Though injectable thermoplasticized guttapercha technique has better sealability but extrusion of the material was seen in almost all the specimens of this group. This extrusion may affect the prognosis when used clinically. Haddix et al reported that the teeth obturated with the thermoplasticized guttapercha exhibited extrusion of the guttapercha from the apex during the obturation procedure when an apical opening created by passing a no.10 file $1 \mathrm{~mm}$ through the apex is large enough to permit extrusion of guttapercha. ${ }^{22}$ Hence he suggested that to prevent over extrusion clinically, the dentist should test for an apical 
barrier with a no. $10 \mathrm{~K}$ type file after biomechanical preparation is completed. In cases in which the apical barrier does not prohibit the passage of no. $10 \mathrm{~K}$ file beyond the working length, obturation with the lateral condensation technique should be strongly considered. As the apical barrier of all the specimens in the present study was crossed with a no. $10 \mathrm{~K}$ file this may explain the apical extrusion in group II.

As it was an in vitro study increase in external root surface temperature was of not so much importance but when this system will be used clinically than importance of rise of external root surface will be of much importance so needs to be tested. Lipski revealed that the use of injectable guttapercha heated to $160^{\circ} \mathrm{C}$ into the root canal of maxillary central incisors produces temperature on the outer root surfaces below the critical level and therefore should not cause damage to supporting periradicular tissues whereas the root canal space of mandibular central incisors resulted in an elevation of root surface temperature above critical level. ${ }^{9}$

As there is no significant difference between lateral condensation technique and downpack backfill technique; lateral condensation and thermafil. The results of this study are in concurrence with those of $\mathrm{Wu}$ et al, Maden et al, De-Deus et al who also found no statistically significant difference between the sealing ability of lateral condensation technique, warm vertical condensation( System B+Obtura II) in oval canals. ${ }^{23,24,25}$ Though they found the canal filled area to be greater with warm guttapercha technique than with cold guttapercha technique in oval shaped canals.

The result of our study are in concurrence with De Deus et al, Schafer et al who evaluated that there was no statistically significant difference between the sealing ability of thermafil and lateral condensation for obturation of oval shaped canals. ${ }^{25,26}$ Beatty et al in his study found that there is a significant difference between lateral condensation technique and thermafil technique. ${ }^{27}$ The variation in results may be due to the variation in specimens, testing procedures and operator skills in which methylene blue dye was used as a tracer and dye penetration was measured after splitting the roots longitudinally.

In our study thermaflo technique was better than thermoplasticized guttapercha using E \& Q plus with down pack Backfill technique and there was significant difference between two techniques. The results of our study are in concurrence with Gencoglu et al in which Thermafil was found to be superior to system B+ Obturall in term of core to sealer ratio. ${ }^{28}$ Prasanth et al also reported that thermafil showed significantly higher percentage of guttapercha filled area than E\&Q plus with down pack Backfill technique. ${ }^{10}$

The results of our study were not in concurrence with the study of Qiong Xu et al showed no significant difference between thermafil \& E \& Q Plus. ${ }^{2}$ This may be because of difference in methodology as they use glucose leakage test for evaluation of sealing ability.

The results from in vitro studies for sealing ability however cannot be exactly extrapolated to in vivo conditions till now. Pommel investigated sealing ability of different obturation techniques by using fluid filtration, electrochemical and dye leakage methods. ${ }^{29}$ They found no correlations among the results obtained with the three methods of evaluation. Therefore more research needs to be done about the methodology of leakage tests and standardization is needed for test protocols.

As in this study only clearing technique was used to evaluate sealing ability of different obturation technique by measuring linear dye penetration. More parameters need to be evaluated like core sealer ratio, presence of voids, replication of depressions and intra canal defects by viewing longitudinal and horizontal sections after sectioning the teeth or by using split model technique to consider that which obturation technique is the best in reality. Furthermore these findings need to be correlated with clinical performance.

\section{REFERENCES}

1. Ingle JI, Bakland LK. Endodontics. 5th ed. Hamilton (ON): BC Decker; 2002.

2. Xu Q., Jungi ling, Cheung G. S.P, Yan Hu. : A quantative evaluation of sealing ability of obturation techniques by using a glucose leakage test. Oral Surg Oral Med Oral Pathol Oral Radiol Endod 2007; 104: e109-e113. 
3. Brayton SM, Davis SR, Goldman M. Guttapercha root canal fillings. An in vitro analysis Part I. Oral Surg. Oral Med. Oral Path 1973; 35: 226-231.

4. Meister F, Lommel TJ, Gersten H. Diagnosis \& possible causes of vertical root fracture. Oral Surg. Oral Med. Oral Path 1980; 49: 243-53.

5. Gimlin DR, Parr CH, Aguirre RG. A comparison of stresses produced during lateral and vertical condensation using engineering models. J Endod 1986; 12:235.

6. Wu MK, Wesserlink PR. A primary observation on the preparation and obturation of oval canals. Int Endod J 2001; 34: 137-141.

7. Yee, FS, Marlin J, Krakow, AA, Gron P. Three dimensional obturation of the root canal using injection-molded, thermoplasticized dental gutta-percha. J Endod 1977; 3:168.

8. Gutmann JL. \& Rakusin H. Perspectives on root canal obturation with thermoplasticized injectable guttapercha. Int Endod J 1987; 20: 261-270.

9. Lipski M. In Vitro Infrared thermographic assessment of root surface temperature generated by high temperature thermoplasticized injectable guttapercha obturation techniques. J.Endod 2006; 32: 438-441.

10. Prashanth BR, Vasundhara S. Analysis of percentage of guttapercha filled area using single cone, continuous wave of compaction, thermafil \& obtura II in 0.06 taper prepared root canals. Endodontology

11. Johnson WB. A new Guttapercha Technique. J Endod 1978; 4:184-187.

12. Robertson D, Leeb JI, Mckee M, Brewer E. A clearing technique for the study of root canal Systems. J Endod 1980; 6: 421-4.

13. Grossman LI Endodontic Practice, 10th Edition. Philadelphia, USA: Lea \& Febiger.

14. Tagger MA, Katz A, Tamse A. Apical seal using the GP II method in straight canals compared with lateral condensation with and without sealer. Oral Surg Oral Med Oral Pathol Oral Radiol Endod 1994; 78:225-31.

15. Abarca AM, Bustos A, Navia M. A Comparison of apical sealing and extrusion between thermafil and lateral condensation techniques. J Endod 2001;27:670-672.

16. Fox, Gutteridge. An in vitro study of coronal microleakage in root canal treated teeth restored by the post and core technique. International Endod J. 1997; 30(6): 361-8.
17. Katz A, Rosenwasser R, Tamse A. Root positioning and leakage to dye in extracted teeth using reduced pressure. Int Endod. Journal 1998; 31: 63-66.

18. Pathomvanich S., Edmunds DH. Variation in microleakage produced from different techniques in root filling in a simulated root canal model. International. Endodontic Journal 1996; 29:156-62.

19. Torabinejad M, Skobe Z, Trombly PL, Krakow AA, Gron P, Marlin J. Scanning electron microscopic study of root canal obturation using thermoplasticized guttapercha. J Endod 1978; 4:245-249.

20. McRobert AS, Lumley PJ. An in vitro investigation of coronal leakage with three guttapercha back filling techniques. Int Endod J 1997; 30:413-417.

21. Weller N, Kimbrough WF, Anderson RW. A comparison of thermoplastic Obturation Techniques: Adaptation to Canals Walls. J Endod 1997; 23:703-706.

22. Haddix JE, Jarrell M, Mattison GD, Pink FE. An in vitro investigation of the seal produced by a new thermoplasticized guttapercha obturation technique. Quintessence International. 1991;22: 159-163.

23. Wu MK,Kastakova A, Wesserlink PR . Quality of cold and warm guttapercha fillings in oval canals in mandibular premolars. Int Endod J 2001; 34; 485 - 491.

24. Maden M, Gorgul G, Tinaz AC. Evaluation of Apical Leakage of Root Canals Obturated with Nd:YaG laser-softened Guttapercha, System-B, and Lateral Condensation Techniques. J Contemp Dent Pract 2002; (3)1: 016-026.

25. De Deus G, Murad CF, Reis CM, Filho EG, Filho TC, Analysis of sealing ability of different obturation techniques in oval shaped canals: A study using a bacterial leakage model. Braz Oral Res 2006; 20(1):64-9.

26. Schafer E, Doz P, Oithoff G. Effect of three different sealers on the sealing ability of both thermafil obturators and cold laterally compacted guttapercha. J Endod 2002; 23:638 -642.

27. Beatty RG, Baker PS, Haddix J, Hart A. The efficacy of four root canal obturation techniques in preventing apical dye penetration. J Am Dent Assoc 1989; 119:633-637.

28. Gencoglu N.Comparison of 6 different guttapercha techniques (Part II): Thermafil, JS Quick -Fill, Soft Core, Microseal, System B, and lateral condensation. Oral Surg Oral Med Oral Pathol Oral Radiol Endod 2003; 96: 91-5.

29. Pommel L. Lack of correlation among three methods for evaluation of apical leakage. J Endod 2001;27:347-350. 